\title{
Augmenting course delivery and evaluation of undergraduate and postgraduate engineering courses with MOOCs
}

\author{
Satyajit R. Patil \\ Automobile Engg. Dept., Rajarambapu Institute of \\ Technology, Rajaramnagar, Dist. Sangli \\ (Maharashtra State) India - 415414 \\ satyajit.patil@ ritindia.edu
}

\begin{abstract}
This work makes an effort to explore the use of MOOCs as a tool to augment traditional course delivery as well as effective evaluation of student performance. The experience and findings of an effort to use two MOOCs on the edX platform offered by Delft University, Netherlands for augmenting course delivery and evaluation for an undergraduate and postgraduate level course on electric and hybrid electric vehicles are shared. The hypothesis proposed in this work is, MOOCs can effectively supplement conventional mode of classroom delivery i.e. classroom lecturing and; simultaneously could be used for student assessment over the period of course delivery indicating the attainment of the intended outcomes of the course. The methodology adopted for the utilization of the MOOCs is elaborated. The purpose of student engagement and effective evaluation of student performance is well served by augmenting the course delivery and evaluation with the help of MOOCs.
\end{abstract}

Keywords: MOOCs, course delivery, student evaluation, student engagement

\section{Introduction}

Effective student engagement is a major prerequisite for the implementation of outcomes-based education philosophy. With further reducing the attention span of the students in the classroom, it is imperative to keep them interested in the course content and challenge their imagination. Various active learning techniques have been suggested for effective course

\begin{abstract}
Satyajit R. Patil
Automobile Engg. Dept., Rajarambapu Institute of Technology, Rajaramnagar, Dist. Sangli

(Maharashtra State) India - 415414

satyajit.patil@ ritindia.edu

delivery of engineering courses. Some of these include share and pair, jigsaw puzzle, one-minute seminar etc. Evaluation of the students' performance is the subsequent challenge that the course instructor meets. The evaluation method/s should be fair, transparent and validate the learning outcomes intended at the beginning of course delivery. Various evaluation methods practiced in engineering education are quizzes, assignments, theory and practical examinations, openbook tests to name a few.
\end{abstract}

Massive Open Online Course (MOOC) is defined as 'an online course aimed at unlimited participation and open access via the web' [1]. It offers resource material for a course in the form of course notes, problem sets, recorded lectures etc. In addition to this, it facilitates interaction among the course instructor and the students (participants) through discussion forums. The students can take quizzes and upload the assignment through which the student performance could be assessed. MOOCs have recently been emerged as popular tools for learning owing to its flexibility and ease of access. There are platforms like edX, Coursera, Udemy, NPTEL and so on, which offer MOOCs on various engineering domains designed and delivered by universities and institutes of repute. Many of these MOOCs are free for the learners. The learners are required to pay so as to obtain a certificate on successful completion of the course content. 


\section{Literature review}

There has been research on various facets of MOOCs at the national and international levels. In fact, MOOCs have emerged as a challenging area for researchers across the globe and faculty. The feasibility of MOOCs and a variety of issues with regards to engineering education have been addressed to a certain extent.

Fournier et al. [2] presented challenges to research on MOOCs and insisted on a significant amount of qualitative and quantitative data to draw conclusions. Olazabalaga et al. [3] presented trends and methodologies of research on MOOCs. They highlighted the two most promising research trends viz. interest in hybrid MOOCs and students' learning results. The work presented technological, pedagogical and strategic aspects of MOOCs research trends. Rauf et al. [4] carried a literature review on the use of MOOCs in engineering education. The study presented various models of MOOCs being adopted worldwide and students' satisfaction in terms of learning achieved through the MOOCs. The authors concluded that MOOCs will be used extensively by engineering institutions in the near future, despite their limitations. Abeer and Miri [5] researched the influence of student basic competencies and design features of MOOCs, on student retention and interest in the MOOC. Kajimoto [6] shared his experiences of integrating a MOOC into on-campus teaching. MIT and Harvard University have reported key findings on learner engagement in MITx and HarvardX courses launched between the summer of 2012 and the fall of 2016 [7]. Issues of MOOCs in the Indian context have been discussed and presented by Chatterjee and Nath [8], Chauhan [9] and Devgan [10]. Phatak [11] proposed the concept of blended MOOCs for higher education in India and shared his own experiences from IIT Bombay. According to him, owing to limitations like 'disintermediation of human interaction' and lack of practical sessions, MOOCs will at best complement the present system and not substitute. He also fetches attention to the significantly higher rate of dropouts for the MOOCs worldwide. Rao et al. [12] suggested a model for Indian universities wherein credits are to be offered on successful completion of MOOCs selected by the university and affiliated colleges. They presented opportunities offered and challenges to be overcome for the use of MOOCs and advocated MOOCs for quality mass education in India. Arya [13] presented an analysis of textual incidences for Asian countries with a particular focus on India. Chakravarty and Kaur [14] described MOOC as an effective tool for scaling up school education as well as higher education in India. They compared advantages of MOOCs along with limitations and informed about MOOC platforms like
NPTEL, e-PG Pathshala and ApnaCourse in India. Joshi et al. [15] carried out an ethnographic study at Ameerpet, Hyderabad, India's prominent IT skilling hub in order to investigate student's preference for the physical model of learning to virtual learning platforms. This research led them to offer suggestions for online learning platforms in terms of job -readiness to attract the students. Shailaja and Prathikantham [16] presented the results of the survey carried out with an objective to understand the implications of MOOCs in engineering education in India. They addressed critical issues like motivation, enormous enrollment, retention and interaction, plagiarism and cheating, and success rate with regard to MOOC adoption.

The literature review indicates that the papers addressing MOOCs for education, in general, are ample in number, however, those with a particular focus on engineering education are scarce. Though various issues of MOOCs such as technology, social implications, and student preferences are addressed, the studies presenting first-hand accounts of deployment of $\mathrm{MOOC} / \mathrm{s}$ for delivering and evaluation of an engineering course in blended approach are very few. This work makes an effort to explore the use of MOOCs as a tool to augment traditional course delivery as well as effective evaluation of student performance. The hypothesis proposed in this work is MOOCs can effectively supplement conventional mode of classroom delivery i.e. classroom lecturing and; simultaneously could be used for student assessment over the period of course delivery indicating the attainment of the intended outcomes of the course. The work presents the utilization of two MOOCs offered by Delft University, Netherlands for delivering two courses on electric and hybrid electric vehicles at Automobile engineering undergraduate and postgraduate programs. The methodology adopted has been presented which is followed by elaborate results and discussions. The conclusion is drawn based on this experience.

\section{Methodology adopted}

Considering the emergence of electric and hybrid electric vehicles and the mobility options offered thereby, courses covering the electric and hybrid electric vehicle technology are introduced in the curriculum of Automobile Engineering undergraduate and postgraduate programs. The courses delivered at the undergraduate and postgraduate levels are listed in Table 1.

Table 1 Courses supplemented by MOOCs

\begin{tabular}{|l|l|l|l|}
\hline $\begin{array}{l}\text { Sr. } \\
\text { No. }\end{array}$ & $\begin{array}{l}\text { Course } \\
\text { code }\end{array}$ & Course title & Level \\
\hline 01 & AE 4061 & $\begin{array}{l}\text { Electric and } \\
\text { hybrid } \\
\text { electric }\end{array}$ & $\begin{array}{l}\text { Final year } \\
\text { B. Tech. } \\
\text { Automobile }\end{array}$ \\
\hline
\end{tabular}




\begin{tabular}{|l|l|l|l|}
\hline & & $\begin{array}{l}\text { vehicle } \\
\text { technology }\end{array}$ & \\
\hline 02 & AUT & $\begin{array}{l}\text { Design of } \\
\text { electric and } \\
\text { hybrid } \\
\text { electric } \\
\text { vehicles }\end{array}$ & $\begin{array}{l}\text { First-year } \\
\text { M. Tech. } \\
\text { Automobile }\end{array}$ \\
\hline
\end{tabular}

The focus of the undergraduate program is on the technology aspect while the course for postgraduate program deals with the technology aspect as well as design challenges of electric mobility. Following Massive Open Online Courses (MOOCs) were being offered on the edX platform by Delft University of Technology, Netherlands as listed in Table 2 when the courses were about to be delivered to the students in odd semester of the academic year 2018-19.

Table 2 List of MOOCs offered by Delft University at edX during 2018

\begin{tabular}{|l|l|c|}
\hline $\begin{array}{l}\text { Sr. } \\
\text { No. }\end{array}$ & Course title (MOOC) & Duration \\
\hline 01 & $\begin{array}{l}\text { Electric cars: } \\
\text { introduction }\end{array}$ & Four weeks \\
\hline 02 & $\begin{array}{l}\text { Electric cars: } \\
\text { technology }\end{array}$ & Four weeks \\
\hline 03 & Electric cars: business & Four weeks \\
\hline 04 & Electric cars: policy & Four weeks \\
\hline
\end{tabular}

As seen, all these courses were of four weeks duration and self-paced; and hence it was possible for the students to complete the chosen course within a semester. The course titled 'Electric cars: introduction', a basic course in the series of courses on 'Electric cars' offered an overview of the technology, business and policy aspects of electric mobility and the industry. Though the technology aspect is well covered in the course syllabus, business and policy aspects of the electric vehicle $(\mathrm{EV})$ industry are not part of the same. Hence, this course was chosen for the undergraduate level so that the students get exposed to the business and policy aspects in addition to the technology aspect of electric mobility. For postgraduate course, the other MOOC titled, 'Electric cars: technology' was chosen as the program demands the depth within the domain. This MOOC was a specialized one and treated the EV technology elements like battery, electric drives and control in depth. The other two MOOCs were specialized and more suitable for non-engineering programs.

The following process/scheme was adopted for supplementing the course with the MOOCs from the delivery and evaluation perspective.

1. Students were briefed about these MOOCs, their relevance with respect to the course and possible benefits from these MOOCs.

2. The students registered for the MOOCs within the agreed-upon time window of a week.
3. An agreement was reached among the course instructor and the students with regard to milestones and dates to reach. eg. completion of Technology module, completion of Business module and completion of Policy module.

4. The evaluation plans were prepared and shared with the students by the course instructor. Fig. 1(a) shows the evaluation plan for the undergraduate course (AE 4061) and Fig. 1 (b) shows the same for the post-graduation program course (AUT1083).

5. The course content in the curriculum was being delivered throughout the semester to the respective classes in accordance with the course plan that was shared with the students at the beginning of the semester.

6. The formal and informal review was taken in the classes during the semester. The formal review required the students to produce and show the online status chart showing the progress in terms of completion of the modules. The students are required to take quizzes after studying the resource material in the form of videos, notes etc. The informal review involved reminding the students of the deadlines agreed upon earlier, the evaluation plan shared earlier and interaction to ensure that they are progressing ahead steadily. Discussions were opened up intermittently to summarize the student learnings and outcomes.

7. The students were required to submit the screenshot (Fig. 2) showing the final status with regard to completion of the MOOC.

8. A final quiz was administered based on the classroom delivery as well as the MOOC content.

9. The student performance was evaluated as per the evaluation plan shared earlier based on the completion of the MOOC, the score they obtained in the MOOC, and the score in the final quiz. For the undergraduate program, the students received marks (out of 10,5 and 5 respectively for technology, business and policy modules) for successfully completing the modules on time while for a postgraduate program, it was agreed with the students that there won't be marks for the only completion of the modules of the MOOC.

10. The final feedback was taken from the students after the quiz regarding the course delivery and the MOOC effectiveness. 


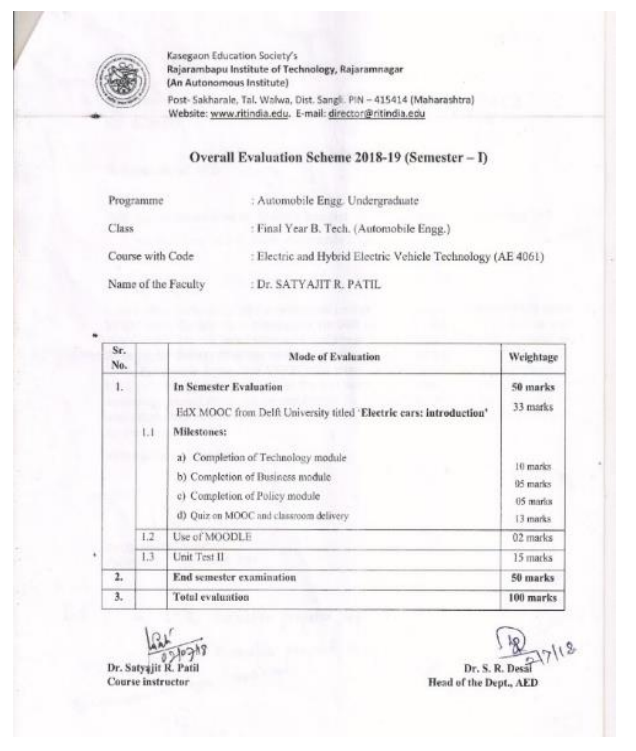

(a) Evaluation plan for AE4061

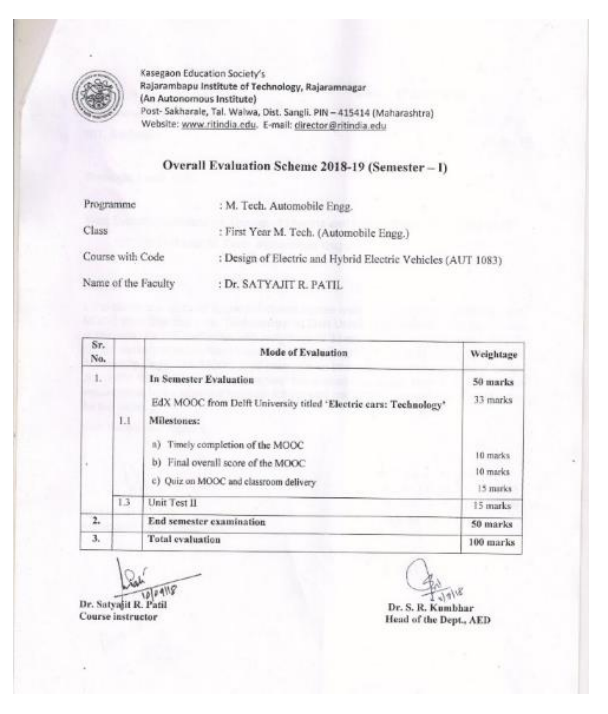

(b) Evaluation plan for AUT 1083

Fig. 1. Evaluation plans
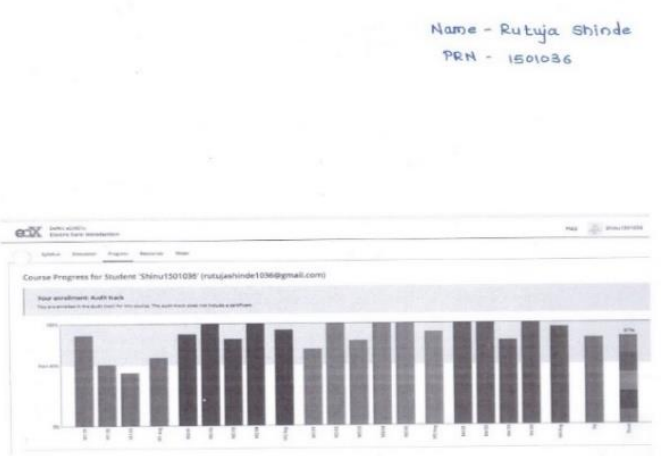

Fig. 2. Screenshot showing the MOOC completion status

\section{Results and discussions}

The number of students registered for the 'Electric cars: introduction' MOOC was 20 while this number was 6 for the 'Electric cars: technology' MOOC. All the students successfully completed the MOOCs. The evaluation was carried out as per the evaluation plan for respective courses. The certificate for the completion of the MOOC was not insisted upon as it would cost around $\$ 50$ to the students. The status was verified for each student based on the progress chart appearing on the platform. The average score was 28.05 out of 35 marks with a maximum score of 33 and the minimum one being 23. The difficulty level of the MOOC 'Electric cars: introduction' could be described as 'slightly moderate' while that of the other MOOC 'Electric cars: technology' could be described as 'moderate'. Along with the difficulty level, the reason for the student score could be attributed to the fact that the idea of adoption of MOOC for course delivery and evaluation was well received by the students and they completed the MOOC with active interest owing to the international context and availability of variety of resources along with the freedom to use them at their own pace and convenience. Based on the feedback session which was conducted right after the final quiz, it could be mentioned that the students enjoyed this different type of experience and were benefitted by taking the MOOC as it complemented the course in the curriculum. The tangible outcomes of this scheme were a variety of learning resources for the students and the instructor as well as objective, continuous and neutral evaluation of students. Exposure to the international university experience raised the level of interest in the course and content beyond the curriculum could be claimed as intangible outcomes of this exercise.

The major drawback of this scheme from the student performance evaluation point of view is that the students take the quizzes for various modules of the MOOC on their own and without the supervision of the instructor. There is a possibility that weak students may take these quizzes with the help of their batch mates and score higher as compared to the score they would obtain if these quizzes are administered to them under the supervision of the instructor. Also, as a final exercise of completion of these MOOCs, the students are required to submit an essay (maximum 500 words) worth 10 points, offering a solution to the question posed to the learners. The mode of assessment for this essay is selfevaluation on the basis of a standard rubric designed by the MOOC instructional team at Delft University. There will be an obvious tendency on the part of the students to grade themselves heavily rather than realistically. This provides another explanation for the higher range of student scores observed. 
The author is of the opinion that in the spirit of the process of education and in the larger interest, it is more important to ensure the student motivation and engagement for learning than the numbers and figures supposedly indicating the learning index of the students. In addition, the use of MOOCs for course delivery and evaluation helped to hone few of the $21^{\text {st }}$ century skills like technology literacy, initiative, flexibility and collaboration among the students.

\section{Conclusion}

This work makes an effort to evaluate the effectiveness of MOOCs for augmenting content delivery and student performance evaluation. Use of two MOOCs on the edX platform titled 'Electric cars: introduction' and 'Electric cars: technology' for an undergraduate and postgraduate level course respectively is reported. The methodology for the adoption of these MOOCs has been presented. The observations and impact with regard to student interest and evaluation along with peculiar limitations are discussed. Based on the overall experience, it is concluded that the proposed hypothesis is true which means, MOOCs supplement the conventional mode of classroom delivery effectively and could be useful as an effective evaluation tool as well. Hence, MOOCs can be considered as an active learning technique for delivering engineering courses. However, it will be interesting to investigate whether MOOCs could substitute the traditional classroom delivery and whether they could be solely relied upon for accurate student evaluation. Future research could be carried out in this direction.

\section{Acknowledgement}

The author acknowledges the guidance and support of Dr. Mrs. S. S. Kulkarni, Director-Rajarambapu Institute of Technology, Rajaramnagar for the work.

\section{References}

1) https://en.wikipedia.org/wiki/Massive_open_online_cour se accessed on $25^{\text {th }}$ June 2019.

2) Fournier H, Kop R, Durand G. Challenges to research in MOOCs. MERLOT Journal of Online Learning and Teaching. 2014 Mar 1; 10(1).

3) Olazabalaga I M, Garrido C C, Ruiz U G., Research on MOOCs: Trends and technologies. Monografico I. 2016 Sept. ISSN: 1697-7467 87-98

4) Rauf AS, Daud MF, Said MN. MOOCs in Engineering Education-A Literature Review. Regional Conference on Engineering Education 2016
5) Abeer W, Miri B. Students' preferences and views about learning in a MOOC. Procedia-Social and Behavioral Sciences. 2014 Oct 7; 152:318-23.

6) https://blog.edx.org/integrating-a-mooc-into-oncampus-teaching?track $=$ blog accessed on $24^{\text {th }}$ June 2019.

7) https://blog.edx.org/study-moocs-offers-insights-onlinelearner-engagement-behavior?track $=$ blog accessed on $24^{\text {th }}$ June 2019.

8) Chatterjee P, Nath A. Massive open online courses (MOOCs) in education-A case study in Indian context and vision to ubiquitous learning. In2014 IEEE International Conference on MOOC, Innovation and Technology in Education (MITE) 2014 Dec 19 (pp. 3641). IEEE.

9) Chauhan J. An overview of Mooc in India. International Journal of Computer Trends and Technology. 2017; 49(2):111-20.

10) Devgun P. Prospects for success of MOOC in higher education in India. International Journal of Information and Computation Technology. 2013; 3(7):641-6.

11) Phatak DB. Adopting MOOCs for quality engineering education in India. InProceedings of the International Conference on Transformations in Engineering Education 2015 (pp. 11-23). Springer, New Delhi.

12) Rao PN, Komaraiah M, Reddy PN. A case for MOOCs in Indian higher education system. Journal of Engineering Education Transformations. 2015 Jul 1; 29(1):15-25.

13) Arya U. The Rise of MOOCs (Massive Open Online Courses) and Other Similar Online Courses VariantsAnalysis of Textual Incidences in Cyberspace. Journal of Content, Community. 2017:26-33.

14) Chakravarty R, Kaur J. MOOCs in India: Yet to Shine. International Journal of Information Studies \& Libraries. 2016; 1(1):14-21.

15) Meghna Joshi, Tanmay Joshi and Nimmi Rangaswamy. Scaling IT classroomskill tutoring: a case study from India. Conference on human factors in computing systems. (CHI 2018) Montreal, Canada

16) Shailaja J, Prathikantham S. Survey on Understanding the implications of MOOCs in Engineering Education. Journal of Engineering Education Transformations. 2018 Jan 1. 